\title{
The Effect of Corpus Assisted Creative Writing Sessions on Intermediate Learners' Writing Skills at the Arab International University
}

\author{
Ranwa Khorsheed \\ Arab International University, Damascus, Syria
}

\begin{abstract}
This paper aims at investigating the progress achieved by a group of intermediate English language learners in creative writing sessions. The main tool used for assessing learners' writing was the online British National Corpus. The learners were trained to use and consult the BNC in a couple of sessions. Then, they were asked to write two descriptive excerpts of a natural scene; one without consulting the $\mathrm{BNC}$ and the other one was done with the aid of the BNC. When comparing the two excerpts, several developments were noted with regard to the learners' use of vocabulary and grammatical structures.
\end{abstract}

Index Terms - BNC, creative writing, grammar, intermediate language learners

\section{INTRODUCTION}

Introducing technology in to language classrooms has proven to be highly effective. With the lapse of years, linguists and lexicographers have managed to create on line linguistic storage of the English language. This on line storage includes hundreds of various examples of different structures, vocabulary and contexts. In addition, users of this storage could easily get to the original text of any example since it already exists as part of the storage. This storage, known as corpora, has been used in language classrooms for different purposes. It is worth noting that introducing corpora to foreign or second language learners, even language instructors, has been of great benefit. It has helped in developing learners' linguistic skills and aiding language instructors in their language classes (Chambers and Bax,2006; Chambers, 2007).

The importance of using corpora in the language classroom:

Training to use corpora would enhance the concept of "language learners as researchers". This is due to the fact that learners would be dealing with corpora as a resource that will help them look up solutions for the mistakes in their writings (Kennedy and Miceli, 2010). There are numerous valuable linguistic benefits offered by online corpora. Working with a corpus could develop learners' process oriented view of language learning (Gabrielatos,2005; O'Sullivan, 2007). In addition, learners would value the relation between form and meaning when examining concordances and would pay much attention to the relation of words and context (Aston, 2001; Gaviol, 1997; Milton, 1999). Furthermore, the use of corpus would raise learners' grammatical consciousness as they receive systematic feedback and examples (Cobb \& Gaskell, 2004; Johns, 1991). It is also worth noting that constructivist theories of developmental psychology stress the fact that using corpora would turn language learners in to more active participant in the learning process. In this case learners would construct their own personal meaning of a given experience (Williams and Burden, 1997). Moreover, the use of corpora offers much learning gains beside the linguistic benefits as it requires an increased cognitive work (Cobb, 1997).

Using online corpora in writing classes:

Online corpora have been introduced by many language instructors to learners in writing classes due to its various benefits and uses. Thus, language instructors have tried to familiarize learners with corpora for consultation. This would give their writing a more natural-native-like aspect (Cobb and Gaskell, 2004). On the other hand, experience has shown that the use of dictionaries would not produce natural linguistic structures. However, with proper training sessions on using on line corpora; learners would be able to search and make use of the search results in their writings. It would be possible for them to correct their writing mistakes and pick lexical structures and collocations (Cobb and Gaskell, 2004).

Using corpora in creative writing sessions:

The benefits of using a corpus could be especially noted in creative writing sessions which are the concern of this paper. Using a corpus in creative writing sessions would raise learners' awareness to the importance of phraseology, encourage them to venture beyond their existing repertoire of multi word patterns, and help them adapt the content of their search results and use the offered patterns in a way that fits and serves their writing topics and objectives (Granger and Meunier, 2008; Kennedy and Miceli, 2010; Milton, 1999). On the other hand, using a monolingual corpora (in this case an English one) would help learners improve three main linguistic techniques in writing: pattern hunting, pattern defining, and finding an equivalent in English for their intended ideas (Kennedy and Miceli, 2010). Novice writers could start by looking for an equivalent in English for their ideas. Then, as they get more experienced; they could try the 
pattern hunting technique. In later stages, writer would use a pattern defining technique to check the grammatical and lexicographical accuracy of their writings (Cobb and Gaskell, 2004; Kennedy and Miceli, 2010; Milton, 1999).

The British national corpus:

In 1990, the BNC was first created by a number of known dictionary producers e.g. Rooms, Longman, The British library, and the research centers of Oxford and Lancaster universities. The project was funded by The Science and Engineering Research and the British government (Aston \& Burnard, 1998). Back at the time, there was so much debate of the use of word processors and developing them. Back then, the fastest personal computer would be that of a 386 Microsoft Intel processor. While the largest disc space wouldn't exceed $50 \mathrm{Mb}$. Thus, all the work on such a project like creating an online corpus would require a fully equipped laboratory with much more developed systems such as Unix (Ibid, 1998). It is also worth mentioning that back at the 1990 the idea of a World Wide Web was still something unfamiliar and somehow ambiguous to most people. However, the notion of creating a corpus was well known at least to those in the field. The three pioneers of the art of corpus creation were Cobuild publishers, the brown school, and the Birmingham school This was also a time at which the notion of computerized (electronic) dictionaries emerged (Clear, 1993). It is worth remembering that the project of creating the BNC cost about 1.5 million at that time and the payment was done over a period of three years. Universities who have contributed to this project were fully aware of its importance in the academic field. Amongst those who contributed to the project were professional lexicographers who took part in the creation of famous dictionaries like Collin Cobuild dictionaries. The project was of priority to the British government because of its potential to bring in to the light a notion of "a UK language engineering industry". On the other hand, the British library considered it a kind of new media in the world of knowledge and a competitor to the newly born digital library (Ibid, 1993). Those in charge of the creation of the BNC, had clear aims in mind. They aimed at creating a rich big corpus that is available for free. Another aim was creating a language bank of spoken and written varieties of British English which are modern and synchronic. In addition, the design of the corpus should focus on mentioning word class and include any necessary relevant information like antonyms or synonyms. However, the indirect aims for those commercial partners like dictionary makers, was to improve their products (Ibid, 1993).

How does the BNC work?

When you launch your internet browser to the British National Corpus site, you will basically see a blue interface with some basic information about the BNC and how to use it. If you click on the (search the BNC) button, you would get a search box with some filters and options. Those filters define how many words do you need to see accompanying the word you are looking up whether before or after, these are called collocations. First, you would get the main list of collocations out of context and you would see which of them is the most frequent. By clicking on each of the collocates in the list, you would get new lists with hundreds of examples of strings taken from different contexts. To the left of those lists, is a link to the name of the original source. Clicking on that link would get you to the complete original text or excerpt out of which the example in the results was taken. Furthermore, you could ask for an annotated list of results. This means all the words in the sentences mentioned in the lists of results would be defined by their parts of speech. The BNC website has made it easy for its users to print the list of results in order to be used for different purposes. The BNC could also be downloaded an used offline. However, this requires special information saving devices with certain storage capacity.

\section{The current research context and back ground:}

The foreign languages center at the Arab International University, where this research took place, offers remedial English courses. These courses teach the four basic linguistic skills (reading, writing, listening and speaking) as integral elements of each course. As for the writing skill, learners start by acquiring the basics of writing and gradually develop new techniques as they move up to advanced levels at the FLC. Learners enrolled in pre-intermediate levels (level zero and one) are instructed to write simple one idea paragraphs with two supporting details and a conclusion. In intermediate levels, (level two and three) the learners are instructed to write purposed paragraphs (descriptive, opinion, persuasive and cause \& effect). Then they are required to develop their paragraphs, as a second step in level three, in to complete purposed essays of five paragraphs. When learners finish all four levels, they have to enroll in the academic writing and research course. In this course, learners are instructed to write academic essays of different purposes and to use quoting and referencing techniques.

\section{Research rationale:}

Learners enrolled in the remedial English courses at FLC usually find it difficult to develop their writing skills. Most learners would avoid the writing section whether in the text book activities or exams. Thus, the researcher came up with the idea of holding corpus based creative writing sessions to assist learners in their writing, motivate and encourage them to write. In addition, these sessions aim at reducing learners' fear of attempting writing tasks which stands as the main reason for holding creative writing sessions and not ordinary or typical writing. The researcher believed that holding creative writing sessions would help learners feel at ease while writing since this kind of writing is not necessary bounded by any standard format as it mostly depends on learners' own personal style. Learners could just go about expressing their minds without being restricted to certain steps, ideas or format. It is usually easier to express and describe one's feelings rather than describing or discussing other general knowledge topics. Furthermore, the researcher resorted to using on line corpora as the main instructional tool in the sessions in order to facilitate the writing process 
for the learners. On line corpora would help them pick up the necessary expressions and vocabulary to finish their excerpts.

\section{Methodology}

\section{Instrument:}

The researcher depended solely on the online British national corpus in the writing sessions. The sessions were conducted in a computer lab and each learner used a separate computer.

\section{Participants:}

Twenty learners, who were registered at the FLC remedial English courses, took part in the current research. The learners belonged to the (18-20 years old) age group. It is also worth mentioning that the learners were of different majors, mostly Business administration and information technology engineering.

\section{Procedure:}

The learners had to attend four sessions of 45 minutes each. The first session was dedicated to free descriptive writing. The second session was an introduction to the BNC and its uses. The third session was allocated for writing along with corpora's assistance. The fourth session was dedicated for comparing learners' writings pre and post using corpora. Each session would be further detailed in the coming sections.

The first session:

On the first session, the learners were asked to write a description of a natural scenery using their own imagination. No limits were suggested for the number of words, the kind of details, ideas or the format of writing (essay/paragraph) to be used. At the end of the session, the learners handed their excerpts to the researcher. It is worth noting that the learners were neither guided nor instructed on how or what to write. However, the researcher has also encouraged the learners to write freely without worrying about structural or grammatical issues in order not to stop the flow of their ideas.

\section{The second session:}

On the second session, the learners were introduced to the BNC (British national corpus). The researcher familiarized the learners with the parts, sections, and the specific functions of the built in buttons of the corpus. In addition, the researcher explained the benefits of using an online corpus for checking word synonyms and collocates, picking expressions, and checking grammatical structures. The learners were mainly instructed on how to look for word collocates using the search box and how to limit the number of pre and post collocates of a word. Furthermore, the learners were guided on how to check the original texts of the corpus results they get after searching for collocates.

\section{The third session:}

On the third session, the learners were asked to rewrite the same descriptive excerpts of the natural scenery which they have written on the first session. However, they were not allowed to look back on their old excerpts. But, they were allowed to repeat or use the ideas which they can recall. This time, the learners were asked to consult the BNC before writing any sentence. In the end of the session, the learners handed in their excerpts.

\section{The fourth session:}

On the fourth session, the learners were handed back both of their excerpts. Then, they were asked to compare between the expressions, structures, and mistakes in both excerpts. It is worth noting that both excerpts of each learner were analyzed by the researcher and the results would be fully detailed in further sections. On the end of the session, the learners were asked to provide their feedback and overall evaluation of attending the corpus assisted creative writing sessions. The feedback and the evaluation would be provided in the results analysis section.

\section{In class observation:}

During the third session, while the learners were using the online BNC, several observations were made. First, most learners were looking for collocates of the following words: river, tree, sky, grass, breeze, flowers, birds and sun. Second, the learners have limited the number of word collocates to one post collocate only. Third, the majority of the learners have only made use of the first fifteen concordances (lines) in the results. Finally, a few learners have asked to print out the first two pages of each search results in order to use them.

\section{RESUltS ANALYSIS}

\section{Analysis of learners' excerpts: \\ Pre-corpus consultation:}

When comparing the learners' pre-corpus consulted excerpts to post corpus-consultation excerpts, it was found out that the pre-corpus consulted excerpts had a variety of grammatical and structural mistakes. There were mistakes in using subjunctive pronouns and choosing suitable vocabulary and adjectives e.g.

1- (Us of subjunctive pronouns): When I and Sami were walking.

2- (Use of vocabulary): a- We looked to the trees and floors.

b- I watched to the trees.

c- .. cut my time.

3- (Use of adjectives): a- Walking in the sported city. 
Other mistakes had to do with verb forms, tenses, prepositions, word order, definite articles and spelling e.g.

1- (Tenses): Speaking about a past experience: a- It is very nice.

2- (Prepositions): a- We started looking about us. b- I watched to the trees.

3- (Word order): a- We must go to the course English.

4- (Definite articles): a- .. the few of people.

5- (Spelling): a- .. clod area.

b- .. new bron.

c- .. specule sound.

It is worth adding that these excerpts (50\%) are short (15 words only) in general, simple, and depict the learners' personal experiences. Nevertheless, these were error free. The shortness of the excerpts could be explained by the learners' fear of extending their writings lest they commit mistakes.

\section{Post- corpus consultation:}

The post-corpus consultation excerpts have fewer mistakes and are longer than pre-corpus consultation ones. The excerpts are generally longer and some $(25 \%)$ are distinguished with a poetic or novel like style which did not exist before corpus consultation e.g.

a- He looked to the moon. "Where is it?"

b- When he looked to the sky.

This could be explained by the learners' attempt to imitate some of the original texts of the results in the concordances. In addition, the excerpts with the poetic style were 50\% off topic e.g.

a- Even the dark night could't cover her beauty.

However, their originality is still attributed to the learners. Furthermore, the learners who submitted short error free pre-corpus consultation excerpts (50\%) have submitted well written post-corpus consultation excerpts. They managed to extract complete expressions from concordances and put them together in perfect coherent sentences without adding any other sentences of their own e.g.

a- As the sun rose higher in the cloudless sky.

b- Bright spring yellow flowers crowding front gardens.

c- I opened my curtains that morning,I saw the sun shining in a cloudless sky.

The last group of learners (25\%) submitted post- corpus consulting excerpts with incoherent expressions which mostly do not fall in a logical order e.g.

a- We used to play cricket, football, marbles and pitch card and the trees in the park misted over young green.

These learners have added a few sentences of their own in the introduction of their excerpts e.g.

a- In the morning I wake up.

b- I open my house door to go to school.

Add to that some spelling, subject-verb agreement, word form, and verb form mistakes were spotted as well in the extracted expressions e.g.

1- (Subject--verb agreement): a- There are a fruit tree in my garden.

2- (Spelling): a- ... becouse I saw the sun.

3- (Word form): a- This is a great natural.

b- I see this natural every day.

4- (Verb form): a-. . to beginning a great day.

\section{DISCUSSION AND CONCLUSIONS}

\section{Results discussion:}

After analyzing the results of the current research, it could be said that corpus-assisted creative writing sessions have different influences on different learners. Some learners (25\%) were able to modify their writing style to the extent of upgrading it almost to a literary level. In addition, those learners have managed to avoid a good number of grammatical mistakes. On the other hand, other learners (50\%) have only used their logical skills in extracting the right expressions and linking them coherently without adding any sentences of their own. Finally, the last group of learners (25\%) have only managed to select (extract) suitable expressions without being able to link them coherently.

Students' feedback on using corpora:

The participants ,who attended the corpus assisted creative writing sessions, were interviewed at the end as a means of eliciting their own evaluation of the usefulness of the sessions. Thus, after analyzing the total feedback of all the participants, the following results were obtained:

$1-80 \%$ of the learners confirmed the usefulness and convenience of using and consulting corpora.

2- 78\% of the learners stated their tendency to look for verbs more than vocabulary in the corpus.

3- 73\% confirmed their full comprehension of the search results.

4- $70 \%$ admitted checking only about 5 pages of the results sheets and using the first convenient example they find.

5- $60 \%$ attempted picking up whole phrases when they find them convenient.

6- $40 \%$ only consulted their search results in the corpus to correct their mistakes. 
7- $45 \%$ stated that using corpora is demanding time consuming.

\section{Conclusion:}

It could be concluded that corpus assisted creative writing sessions might have several benefits if they are well designed and carried out carefully. Corpus assisted writing would be used to train learners' logical skills in discerning the right order of ideas and the right use of cohesive devices. This could be set as an early training for beginner writers. On the other hand, more experienced or trained writers could make use of online corpora by adopting and adapting different styles and techniques.

\section{Research limitations:}

There are some limitations spotted in the current research. First, more sessions could have been allocated to training on corpus use. In addition, it would have been of more benefit to increase the number of the writing sessions and make them more task-oriented. For instance, more varied writing tasks could be done during the sessions.

\section{REFERENCES}

[1] Aston, G. and Burnard, L. (1998). The BNC handbook: exploring the British National Corpus with SARA. Edinburgh: Edinburgh University Press.

[2] Aston, G. (2001). Learning with corpora: An overview. In G. Aston (Ed). Learning with corpora (pp.7.45). Bologna: CLUEB.

[3] Bernardini, S. (2004). Corpora in the classroom: An overview and some reflections on future developments. In J. Sinclair (Ed). How to use corpora in language teaching (pp.15-36). Amsterdam: John Benjamins.

[4] Braun, S. (2007). Integrating corpus work in to secondary education: From data-driven learning to needs driven corpora. ReCALL, 19 (3), 307-328.

[5] Burton, P., Ng, P., (2001). Developing language awareness through concordancing: Action research and materials development for first year university students in Hong Kong. Paper presented at the ITMELT conference, English language center. Hong Kong.

[6] Chambers, A. (2005). Integrating corpus consultation in language studies. Language learning and technology, 9( 2), 111-125. Retrieved from http://ilt.msu.edu/vol 9 num 2/ chambers/ default.html.

[7] Chambers. A., \& Bax, S. (2006). Making CALL work: Towards normalization. System, 34 (4), 465- 479.

[8] Chambers, A. (2007). Popularizing corpus in consultation by language learners and teachers. In E. Hidalgo, L. Quereda, \& J. Santana (Eds.). Corpora in the foreign language classroom. Selected papers from TaLC 2004 (pp. 3-16). Amsterdam: Rodopi.

[9] Clear, J. H. (1993). 'The British National Corpus' in Delany, P. and Landow, G., ed. The Digital Word: text-based computing in the humanities. Cambridge (Mass), MIT Press, pp.163-187.

[10] Cobb, T. (1997). Is there any measurable learning from hands on concordancing? System 25 (3), 301-315

[11] Gabrielatos, C. (2005). Corpora and language teaching: Just a fling, or wedding bells? TESL-EJ 8(4), A11-37. Retrieved in March 2015 from http://www.tesl- ej.org/wordpress/.

[12] Gavioli, L. (1997). Exploring texts through the concordancer: Guiding the learner. In A. Wichmann, S. Fligelstone, T. McEnery, \& G. Knowles (Eds.), Teaching and language corpora (pp. 83-99). London. Longman.

[13] Gaskell, D. and T. Cobb. (2004). Can learners use concordance feedback for writing errors?. System, 32/3:301-19.

[14] Grangers. S., Tribble. C. (1998). Learner corpus date in the language classroom: From focused instruction and data- driven learning. In : Granger. S. (Ed), Learner English and the computer. Longman: London.

[15] Granger, S., \& Meunier, F. (2008). Phraseology in language learning and teaching: Where to from here? In S. Granger \& F. Meunier (Eds.), Phraseology in foreign language learning and teaching Amsterdam: John Benjamins. ELT Journal. Nov. 11 pp. 237-252.

[16] Hunston, S. (2002). Corpora in applied linguistics. Cambridge university press, Cambridge.

[17] Johns. T. (1988). Where and wither classroom concordancing; in: Bongerts, T. et al. (Eds). Computer applications in language learning, 9-27. Foris: Dordrecht.

[18] Kennedy, C., \& Miceli, T. (2010). Corpus-assisted Creative Writing: Introducing intermediate Italian Learners to a Corpus as a Reference Resource. Language Learning and Technology. Feb, Vol 14, Num 1, pp.28-44.

[19] Milton, J. (1999). Lexical thickets and electronic gateways: Making text accessible by novice writers. In C. Candlin \& K. Hyland (Eds.), Writing: Texts, processes and practices (pp. 221-243). London: Longman.

[20] O'Sullivan, I. (2007). Enhancing a process-oriented approach to literacy and language learning: The role of corpus consultation literacy. ReCALL, 19(3), 269-286.

[21] Truscott, J. (1996). The case against grammar correction in L2 writing classes. Language learning 46, 327-369.

[22] Todd, R.W. (2001). Induction from self-selected concordances and self- correction. System, 29/I: 91-102.

[23] Vance, S., (1995). Concordances with language learners: Why? When? What?. CAELL Journal, vol. 6. No 2. 234-250.

[24] Wichmann, A., S. Fligelstone, A. McEnery and G. Knowles (Eds). (1997). Teaching and language corpora. Longman: London.

[25] Williams, M., R. Burden. (1997). Psychology for language teachers: A social constructivist approach. Cambridge: Cambridge University press.

[26] Zahar, R., Cobb, T., Spada, N. (2001). Acquiring vocabulary through reading: effects of frequency and contextual richness. Canadian Modern Language review 57(4), 541- 572.

Ranwa Khorsheed. Born in Damascus, Syria, June, 1984. Studied English language and literature at Damascus university. Got a Master degree in general linguistics, Damascus University, 2014.

She worked for private language institutes. Also worked as an English language instructor at Damascus University. (2015-Present) working for the Syrian Virtual University and the Arab international University in Damascus, Syria. 